\title{
Visualization of Tongue Morphology: An Emerging Mode of Personal Identification
}

\author{
Lakshminarayana Surendra ${ }^{1}$, Vanishri C Haragannavar ${ }^{2}$, Roopa S Rao ${ }^{3}$, Samudrala V Sowmya ${ }^{4}$, Dominic Augustine ${ }^{5}$
}

\begin{abstract}
Aim: The tongue is the only internal organ well encased within the oral cavity, which can be assessed easily by means of inspection and palpation. The shape and physiologic texture of the tongue remains unique to a person. There are various studies on identification of a person using fingerprint, iris scan, skin color, etc., but these modes of identification could be altered by external factors. Hence, we designed a study to identify a person by using the tongue as an identifying tool through the photographic method. Correlation of morphological parameters of the tongue was done through clinical examination and photographic images.

Materials and methods: Total 30 walk-in subjects comprising 15 females and 15 males with an age range 18-65 years were considered in the study. The subjects were analyzed for morphological features of the tongue by clinical examination and the photographic method.

Results: Among 30 subjects, 13 cases showed smooth texture of the tongue, fissured tongue was observed in 14 cases, and 3 cases showed mild fissured. Shape of the tongue was found to be hammered in 10 cases; 9 ellipsoid and 11 rounded shapes were observed. Apex of the tongue was sharp in 9 cases and 21 cases showed a rounded appearance. No cases showed a septate shape. Color of the tongue was whitish in 2 cases, 23 cases were pale pink, and 5 cases were pink.

Conclusion: To conclude, the tongue could replace the other common biometric tools due to its unique features. Further studies with larger sample and advanced techniques are necessary.

Clinical significance: Thus, the tongue could be used as a tool for personal identification by the photographic method.

Keywords: Clinical examination, Forensic dentistry, Oral cavity, Photography, Tongue.

World Journal of Dentistry (2020): 10.5005/jp-journals-10015-1770
\end{abstract}

\section{INTRODUCTION}

The tongue is a unique organ well encased in the oral cavity, which can be easily protruded out and examined through inspection and palpation.' Its unique features like shape, texture, surface, and color can be easily analyzed. Hence, it provides important information to identify an individual by reproducing structure details easily.

According to Chinese medicine, the tongue in a living person has been considered as "tongue of life" due to its color and vasculature. On contrary, it can be described as "tongue of death" because of its dark and withered appearance during the death of a person. $^{2}$

From past 20 years, there has been extensive research on biometrics, which includes physiological and behavioral features of face, ${ }^{1,3-5}$ iris, palmprint, fingerprint, voice, shape of the hand, gait, and the signature. ${ }^{6-8}$ Among these structures, palmprints and fingerprints can be frayed; handshapes, signature, and iris images can be easily scanned. ${ }^{1,9}$ The literature on tongue as a tool for identification of a person is sparse. Hence, we designed a study to identify a person by using tongue as an identifying tool through the photographic method.

\section{Materials and Methods}

The study comprised of 30 walk-in patients visiting the Department of Oral Pathology, Faculty of Dental Sciences-MS Ramaiah University of Applied Sciences, for hematological tests. The subjects were randomly selected between the age group of 18 and 65 years. Patients with pathologies of tongue, habits, and systemic illness were excluded from the study. An informed consent was obtained \begin{tabular}{l}
\hline \hline${ }^{1-5}$ Department of Oral Pathology and Microbiology, Faculty of \\
Dental Sciences, Ramaiah University of Applied Sciences, Bengaluru, \\
Karnataka, India \\
Corresponding Author: Lakshminarayana Surendra, Department of \\
Oral Pathology and Microbiology, Faculty of Dental Sciences, Ramaiah \\
University of Applied Sciences, Bengaluru, Karnataka, India, Phone: \\
+919980424187, e-mail: dr.surendra.8018@gmail.com \\
How to cite this article: Surendra L, Haragannavar VC, Rao RS, et al. \\
Visualization of Tongue Morphology: An Emerging Mode of Personal
\end{tabular} Visualization of Tongue Morphology: An Emerg
Identification. World J Dent 2020;11(6):501-505.

Source of support: Nil

Conflict of interest: None

from every individual before clinical photography and impression making. Prior to the clinical examination, patients were asked to rinse their mouth for better visualization of the tongue surface. The 30 subjects were grouped as group I-15 (male subjects) and group II-15 (female subjects). All the subjects were clinically examined for the morphological parameters of the tongue like color, texture, shape, and apex. These parameters were examined clinically as well as through the photographic method and compared with each other by two observers. The photographs were taken using high-definition NIKON DSLR digital camera. The distance between the camera and the patient's tongue was kept constant with all the subjects by maintaining the same lens magnification throughout the study. During the photography, patients were asked to protrude the tongue in a relaxed position. For the analysis of shape of the

( ) Jaypee Brothers Medical Publishers. 2020 Open Access This article is distributed under the terms of the Creative Commons Attribution 4.0 International License (https://creativecommons.org/licenses/by-nc/4.0/), which permits unrestricted use, distribution, and non-commercial reproduction in any medium, provided you give appropriate credit to the original author(s) and the source, provide a link to the Creative Commons license, and indicate if changes were made. The Creative Commons Public Domain Dedication waiver (http://creativecommons.org/publicdomain/zero/1.0/) applies to the data made available in this article, unless otherwise stated. 
tongue, three reference points were considered like commissures of lip and apex of tongue. ${ }^{1}$ The results were subjected to the Chisquare statistical test using SPSS version 22 .

\section{Results \\ Color of Tongue}

Color of tongue: Out of 30 subjects, 2 showed whitish color, 23pale pink, and 5-pink (Figs 1 and 2, Table 1).

In the present study, three major colors were observed, namely pink, pale pink, and whitish. Among the 30 subjects, pale pink color was found to be more common (76.7\%), followed by pink (16.7\%) and whitish-colored tongue (6.7\%). Between the groups, pale pink was predominant in group I (80\%) compared to group II (73.3\%) followed by pink (13.3\%) and whitish (6.7\%). In group II, $20 \%$ of subjects showed pink and $6.7 \%$ whitish-colored tongue. But, there was a statistically insignificant difference among the color variation with $p$ value of 0.88 .

\section{Texture of Tongue}

Among various forms of textures, the fissured tongue was found to be more predominant (46.7\%) when compared to the bald tongue and mild fissured tongue ( 43.3 and $10 \%$, respectively). In group I, the fissured tongue $(53.3 \%)$ was predominant compared to group II (40.0\%) and in group II, the smooth/bald tongue (53.3\%) was predominant compared to group I (33.3\%). The mild fissured tongue was seen less in number in both the groups (group I-13.3\% and group II-6.7\%) (Table 2, Figs 3 and 4). There was statistically insignificant difference among the texture of the tongue with $p$ value of 0.51

\section{Shape of Tongue}

In the current study, hammered, ellipsoid, and ovoid were commonly noticed shapes of the tongue. Among the 30 subjects, the round-shaped tongue was predominantly seen, followed by hammer- and ellipsoid-shaped tongues (36.7, 33.3, and $30 \%$, respectively). The hammer-shaped tongue was predominant among the group I ( $60 \%, 9$ subjects out of 15$)$ compared to group II $(6.7 \%, 1$ subject out of 15$)$. The ellipsoid shape of tongue was second most common in the present study among both the groups, but it was found to be more predominant in group II (33.3\%, 5 subjects out of 15$)$. The oval-shaped tongue was predominant in group II $(60 \%$, 9 subjects out of 15) compared to group I (13.3\%, 2 subjects out of 15) (Table 3, Figs 5 and 6). The shape of the tongue was found to be statistically significant among the groups with $p$ value of 0.0001

\section{Apex of Tongue}

Among the 30 subjects, 9 cases showed sharp apex (males-6, females-3), 21 subjects showed rounded apex with equal gender predominance (males-9, females-12), and septate shape was not

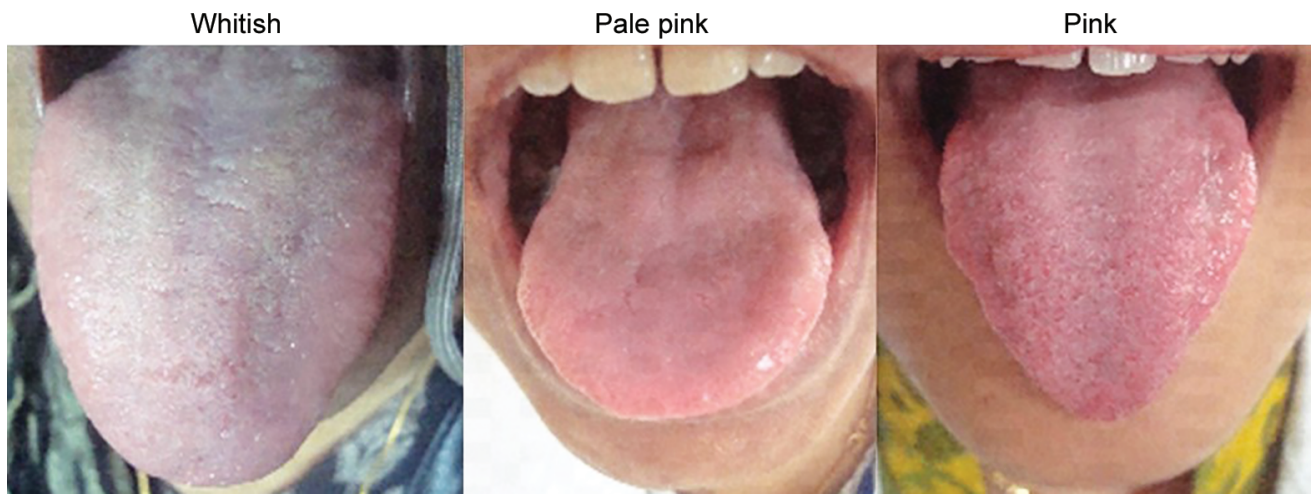

Fig. 1: Color variations of tongue

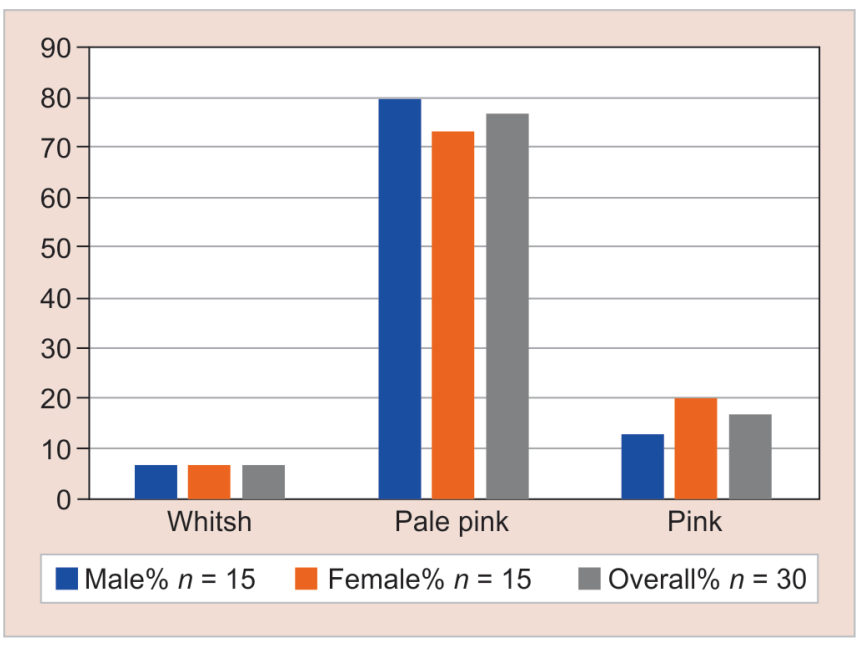

Fig. 2: Color variation of tongue according to gender
Table 1: Percentage of tongue color according to gender

\begin{tabular}{lccc}
\hline Color of tongue & Male\% $(n=15)$ & $\begin{array}{l}\text { Female \% } \\
(n=15)\end{array}$ & $\begin{array}{l}\text { Overall \% } \\
(n=30)\end{array}$ \\
\hline Whitish & $1(6.7)$ & $1(6.7)$ & $2(6.7)$ \\
Pale pink & $12(80.0)$ & $11(73.3)$ & $23(76.7)$ \\
Pink & $2(13.3)$ & $3(20.0)$ & $5(16.7)$ \\
\hline
\end{tabular}

Table 2: Percentage of tongue texture according to gender

\begin{tabular}{llll}
\hline $\begin{array}{l}\text { Texture of } \\
\text { tongue }\end{array}$ & Male\% $(n=15)$ & $\begin{array}{l}\text { Female \% } \\
(n=15)\end{array}$ & $\begin{array}{l}\text { Overall \% } \\
(n=30)\end{array}$ \\
\hline $\begin{array}{l}\text { Smooth/bald } \\
\begin{array}{l}\text { Fissured } \\
\text { tongue }\end{array}\end{array}$ & $5(33.3)$ & $8(53.3)$ & $13(43.3)$ \\
Mild fissured & $2(13.3)$ & $6(40.0)$ & $14(46.7)$ \\
\hline
\end{tabular}




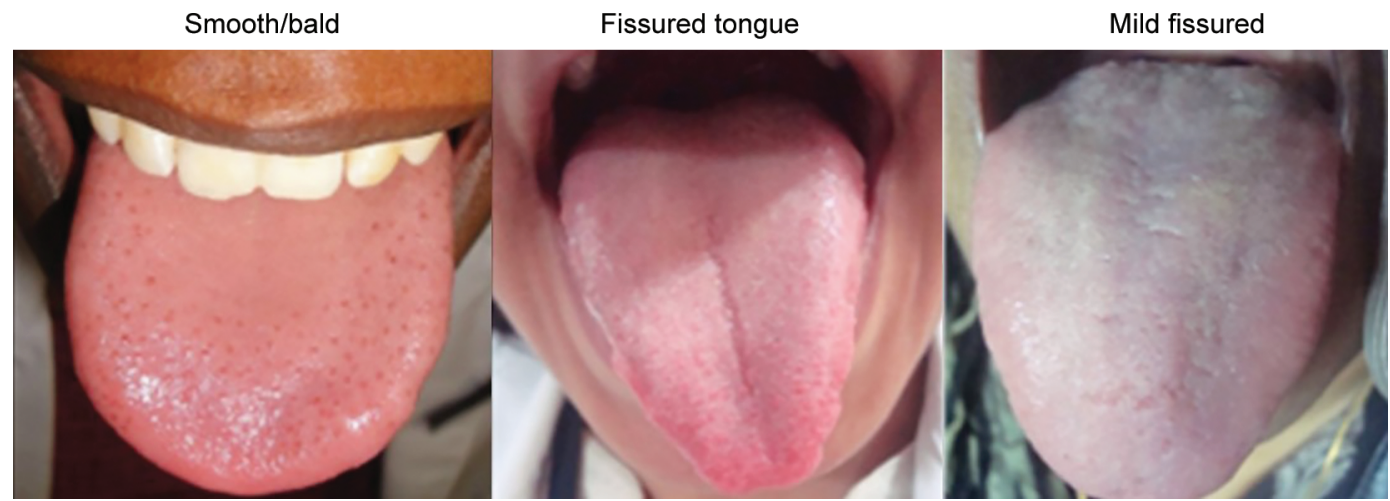

Fig. 3: Texture variations of tongue

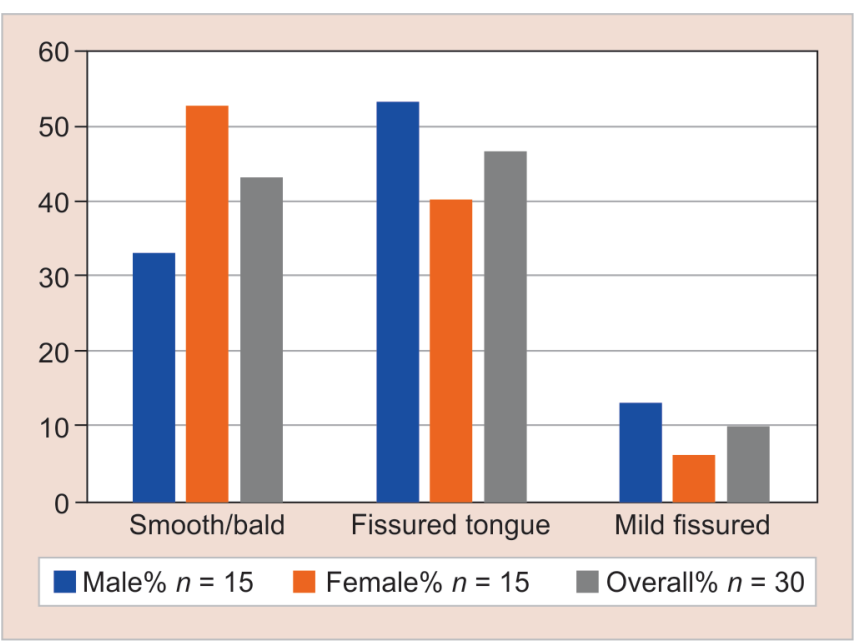

Fig. 4: Texture variation of tongue according to gender

Table 3: Percentage of tongue shapes according to gender

\begin{tabular}{llll}
\hline $\begin{array}{l}\text { Tongue shape } \\
\text { (\%) }\end{array}$ & Male \% $(n=15)$ & $\begin{array}{l}\text { Female \% } \\
(n=15)\end{array}$ & $\begin{array}{l}\text { Overall \% } \\
(n=30)\end{array}$ \\
\hline $\begin{array}{l}\text { Hammered } \\
(66.6)\end{array}$ & $9(60)$ & $1(6.7)$ & $10(33.3)$ \\
$\begin{array}{l}\text { Ellipsoid (30.0) } \\
\text { Round/oval } \\
\text { (66.6) }\end{array}$ & $2(26.7)$ & $5(33.3)$ & $9(30)$ \\
\hline
\end{tabular}

observed in any cases (Table 4, Figs 7 and 8). There was a statistically insignificant difference between the groups for the apex of tongue with $p$ value of 0.23 .

\section{Discussion}

Identification of human beings based on physiological variables is the guidelines for biometric authentication. ${ }^{10}$ The identification of an individual using the tongue was least explored in forensic dentistry. The tongue is an essential organ of human body, which performs various functions, namely speech, taste perception, distribution of food to the occlusal table, and even distribution of saliva within the oral cavity. ${ }^{2}$ It has an essential role in the harmonious function of the oral cavity. The characteristic features present in the tongue are unique from person to person. ${ }^{11}$ Therefore, it is a reliable anatomical structure for personal identification and for biometric purpose..$^{8,12}$ The present study showed the correlation between the clinical and photographic findings of the tongue based on parameters like color, texture, apex, and shape of the tongue.

Color of the tongue, being one of a major parameters in the present study, has been least explored and only one study in the literature by Oji et al. ${ }^{13}$ has mentioned the different colors of the tongue. Our study is the first study to describe the various colors of the tongue with gender association. We have noticed three major colors, namely pink, pale pink, and whitish in the Indian scenario. Among these predominant colors, pink was more predominant; among the genders, the pink-colored tongue was equally noticed in both genders ( males $=12 / 15$; female $=11 / 15$ subjects).

In the present study, hammer, elliptical, and oval-shaped tongues were commonly noticed, which were in accordance with Huang et al. ${ }^{14}$ The current study emphasized on different shapes of the tongue with the gender and we found that the hammer-shaped tongue was predominant in males ( $9 / 15$ subjects) and oval-shaped tongue was predominant in females ( $9 / 15$ subjects). A round-/ oval-shaped tongue ( $9 / 15$ subjects) $(60 \%)$ was more predominant in females, followed by elliptical-(5/15 subjects) (20\%) and hammershaped tongue ( $1 / 15$ subjects) $(20 \%)$.

In the present study, the apex of the tongue observed was rounded and sharper. Among these two forms, rounded apex was predominant compared to the sharper. The rounded apex was predominantly observed in females ( $12 / 15$ subjects) compared to males, which was in contrast to the results of the study by Jeddy et al. They had observed that sharper tongue tips were common among the females compared to male subjects. ${ }^{1}$ In the current study, a round apex was common for both the genders and the septate apex was not noticed in either gender. Stefanescu et al. in a 2014 study showed the rounded apex tongue was more common in males and sharper apex was more common among females, which is in contrast to the present study (9/15 subjects). ${ }^{15}$

In the present study, fissured texture was predominant compared to bald and the minor fissured tongue. Among these, prominent single fissure was the commonly noticed form compared to others with statistically significant $p$ value $=0.011$.

Though various parameters were considered in this study, due to the limited sample size, all the obtained readings were not completely reliable. Therefore, the study has to be investigated on a larger sample size for more reproducible results.

\section{Conclusion}

Photography is a simple methodology to obtain lingual images and tongue surface records is unique that cannot be copied or 


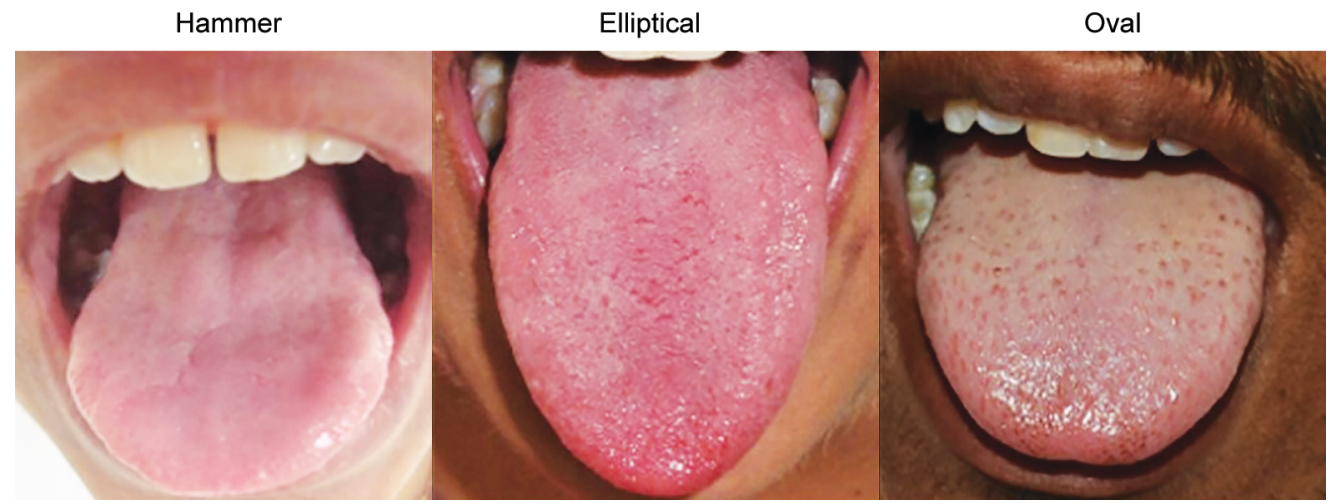

Fig. 5: Shape variations of tongue

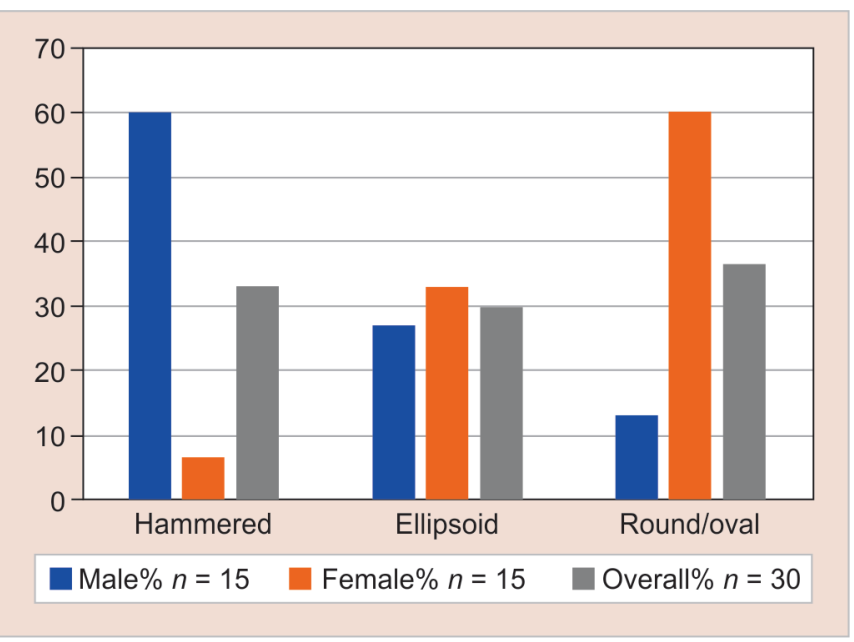

Fig. 6: Shape variation of tongue according to gender

Table 4: Percentage of tongue apex according to gender

\begin{tabular}{llll}
\hline $\begin{array}{l}\text { Shape of tongue } \\
\text { apex }\end{array}$ & Male \% $(n=15)$ & $\begin{array}{l}\text { Female \% } \\
(n=15)\end{array}$ & $\begin{array}{l}\text { Overall \% } \\
(n=30)\end{array}$ \\
\hline Sharp & $6(40)$ & $3(20)$ & $9(30)$ \\
Rounded & $9(60)$ & $12(80)$ & $21(70)$ \\
Septate & 0 & 0 & 0 \\
\hline
\end{tabular}

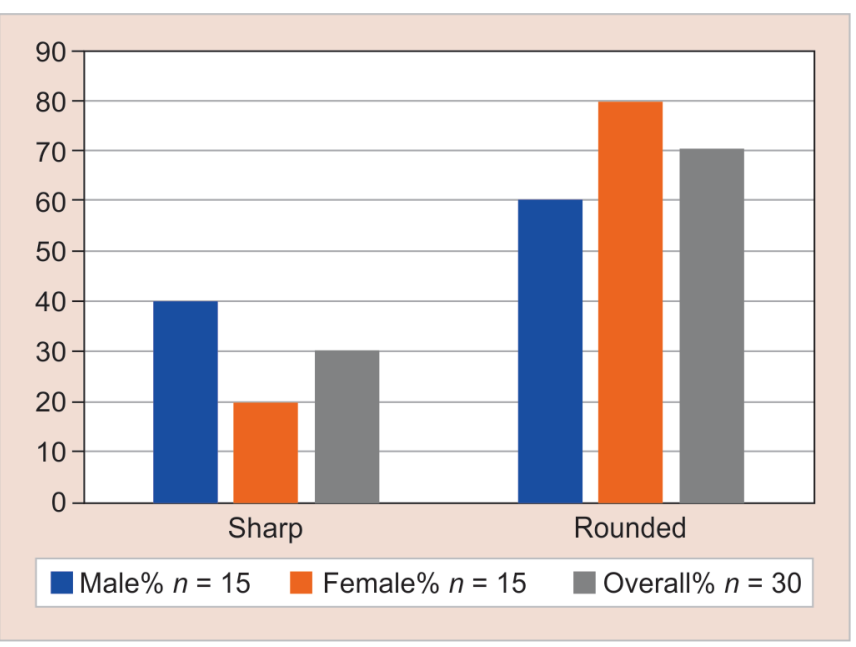

Fig. 8: Apex variation of tongue according to gender

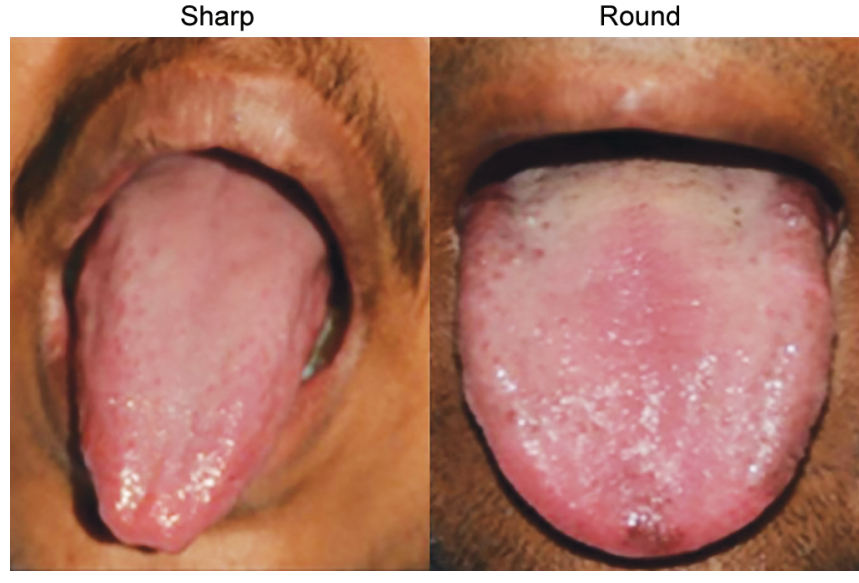

Fig. 7: Variation in apex of tongue

forged. Therefore, it can be used in biometric authentication, since it is personalized and constant. It can be used for person identification in the forensic analysis. However, large-scale studies are recommended to determine the common presentation of tongue features among males and females using advanced techniques and inclusion of stringent criteria.

\section{References}

1. Jeddy N, Radhika T, Nithya S. Tongue prints in biometric authentication: a pilot study. J Oral Maxillofac Pathol: JOMFP 2017;21(1):176-179. DOI: 10.4103/jomfp.JOMFP_185_15.

2. Radhika T, Jeddy N, Nithya S. Tongue prints: a novel biometric and potential forensic tool. J Forensic Dent Sci 2016;8(3):117-119. DOI: 10.4103/0975-1475.195119.

3. Rani JS, Devaraj D, Sukanesh R. A Novel Feature Extraction Technique for Face Recognition. In: International Conference on Computational Intelligence and Multimedia Applications (ICCIMA 2007). IEEE, pp. 428-435.

4. Li C, Barreto A. An Integrated 3D Face-Expression Recognition Approach. In: 2006 IEEE International Conference on Acoustics Speed and Signal Processing Proceedings. IEEE, p. III-1132-III-1135.

5. Garibotto G. Video Surveillance and Biometric Technology Applications. In:2009 Sixth IEEE International Conference on Advanced Video and Signal Based Surveillance. IEEE, pp. 288-288.

6. O'Gorman L, Chatham NJ. Overview of fingerprint verification technologies. Elsevier Inf Secur Tech Rep 1998;3(1):43. DOI: 10.1016/ S1363-4127(98)80015-0.

7. Bhattacharyya $D$, Ranjan R, FA A, et al. Biometric authentication service launched in USA. Int J Serv Sci Technol 2009;2:13-28. 
8. Kaur G, Gaganpreet DS. A novel biometric system based on hybrid fusion speech, signature and tongue. Int J Comput Appl 2015;119(7):30-39. DOI: 10.5120/21082-3764.

9. Stefanescu CL, Popa MF, Candea LS. Preliminary study on the tonguebased forensic identification. Rom J Leg Med 2014;22(4):263-266. DOI: 10.4323/rjlm.2014.263.

10. Diwakar $M$, Manoj D. An extraction and recognition of tongue-print images for biometrics authentication system. Int J Comput Appl 2013;61(3):36-42. DOI: 10.5120/9912-4509.

11. Zhang D, Liu Z, Yan J. Dynamic tongueprint: a novel biometric identifier. Pattern Recognit 2010;43(3):1071-1082. DOI: 10.1016/ j.patcog.2009.09.002.
12. Liu Z, Yan J-Q, Zhang D, et al. A Tongue-Print Image Database for Recognition. In: 2007 International Conference on Machine Learning and Cybernetics. IEEE, pp. 2235-2238.

13. Oji T, Namiki T, Nakaguchi T, et al. Study of factors involved in tongue color diagnosis by Kampo medical practitioners using the FarnsworthMunsell 100 hue test and tongue color images. Evidence-Based Complement Altern Med 2014;2014:1-9. DOI: 10.1155/2014/783102.

14. Huang $B, W u J$, Zhang $D$, et al. Tongue shape classification by geometric features. Inf Sci (Ny) 2010;180(2):312-324. DOI: 10.1016/j. ins.2009.09.016.

15. Sudarshan R, Sree Vijayabala G, Samata Y, et al. Newer classification system for fissured tongue: an epidemiological approach. J Tropi Med 2015. 2015. DOI: 10.1155/2015/262079. 